and the physical stress the dialysis makes in terms of brain metabolism and toxic metabolites in general (Kemph, 1982).

Psychiatric morbidity in relation to the aetiology (Table 5) of the renal failure was reflected in significant differences on the anxiety and hysteria scales. Many variables may play role here, such as type of personality and its relation to susceptibility to physical illness (e.g. those with hypertenson scored more on anxiety), medication (e.g. antihypertensives), type of therapeutic procedure (e.g. surgery) and type of disability the patient has. All these variables need to be studied further.

\section{Acknowledgements}

The authors would like to thank Professor Tom Craig and Professor Simon Wessely for their comments and guidance on the original manuscript.

\section{References}

Aghanwa, H. S. \& Morakinyo, O. (1997) Psychiatric complications of hemodialysis at a kidney center in Nigeria. Journal of Psychosomatic Research, 42, 445-451.

Gurland H. J., Brunner, F. P., Chantler, C., et al (1975) Combined report on regular dialysis and transplantation in Europe. VI. Proceedings of the European Dialysis and Transplant Association, 12, 13-23.

Kemph, J. P. (1982) End-stage renal disease dialysis. Psychiatric Clinics of North America, 5, 407-417

Maghazaji, H. I., Alwash, R., Murtadah, M., et al (1982) Psychoneurotic profiles in Iraqi medical students. British Journal of Medical Psychology, 55, 271-274

Phipps, A. \& Turkington, D. (2001) Psychiatry in the renal unit. Advances in Psychiatric Treatment, 7, 426-432.

Racy, J. (1980) Somatization in Saudi women. A therapeutic challenge. British Journal of Psychiatry, 137, 212-216.

\title{
A 12-year follow-up of a sample of patients dependent upon heroin
}

\section{Saima Niaz, ${ }^{1}$ Nadia Arshad, ${ }^{2}$ Mariam Haroon, ${ }^{3}$ Fahd A. Cheema, ${ }^{4}$ Khalid A. Mufti ${ }^{5}$ and Haroon Rashid Chaudhry ${ }^{6}$}

\begin{abstract}
${ }^{1}$ Assistant Professor, Department of Psychiatry, Fatima Jinnah Medical College/Sir Ganga Ram Hospital, Lahore, Pakistan, email niazpsych@yahoo.com

${ }^{2}$ Deputy Manager Research, College of Physicians and Surgeons, Pakistan ${ }^{3}$ Medical Officer, Department of Psychiatry, Services Hospital, Lahore, Pakistan ${ }^{4}$ Medical Officer, Department of Psychiatry, Fatima Jinnah Medical College/Sir Ganga Ram Hospital, Lahore, Pakistan

${ }^{5}$ Medical Director, Ibadat Hospital, Peshawar, Pakistan ${ }^{6}$ Professor and Head, Department of Psychiatry, Fatima Jinnah Medical College/Sir Ganga Ram Hospital, Lahore, Pakistan
\end{abstract}

Hentan eroin addiction is a chronic, relapsing and remitting condition. Each year $2-5 \%$ of addicts discontinue drug use permanently and 1-2\% die, mostly of overdose (Robins, 1993). A study of 129 opiate-addicted patients on a monthly maintenance regimen found that those with a family history of opium use had an earlier age at onset (Chaudhry et al, 1991). Long-term follow-up studies of people who misuse opiates have revealed that opioid dependence appears to run a chronic, relapsing and remitting course with a significant mortality (10-15\%) over 10 years (Robson, 1992). Metrebian et al (1998) reported that long-term heroin abstinence was associated with less criminality, psychological distress and morbidity; Hser et al (2001) reported it was associated with higher employment rates.

In another study, 78 opiate users were followed up after successful in-patient detoxification. Eleven categories of lapse precipitant were identified: cognitive, mood, external withdrawal, interpersonal, leaving a protected environment, drug availability, drug-related cues, craving, priming, and social pressures and young age (Bacchus et al, 2000). Substantial periods of employment and marriage are pointers to a good outcome (Zhang et al, 2003). Rasheed et al (1992) showed that earlier age at first consumption of the drug was associated with the misuser faring better on substitution programmes.

\section{Method}

This was a hospital-based, 12-year follow-up study. The sample comprised 137 male heroin-dependent patients, aged 20-40 years, admitted to the Free Psychiatric Clinic at Ahbab Hospital. The Clinic, run by grant from the community, has provided services for 22 years. It is located in the urban slums of Lahore. Written consent was obtained. The patients' mean age was 26.4 years at first assessment. Most patients (115) were inhaling heroin, but 22 were smoking it. A semi-structured interview (including demographic details), thin layer chromatography (TLC) and intranasal naloxone challenge tests were used as screening instruments. In the naloxone challenge, papillary response, pulse rate and blood pressure were measured, and TLC is useful for separating organic compounds.

The intervention did not comprise a comprehensive rehabilitation programme for the patients but there were regular educational programmes addressing the hazards of drug addiction during the stay. The average duration of treatment was 2 weeks. The special programmes addressing the hazards of drug addiction were arranged for patients and caregivers fortnightly for 3 months, and later monthly for 9 months (15 sessions in total), with the help of a local non-governmental organisation, Project for Environmental Protection, Antinarcotics Community Education (PEACE). 
Table 1 Distribution of participants by factors associated with relapse

\begin{tabular}{|c|c|c|c|}
\hline $\begin{array}{l}\text { Factors associated with } \\
\text { relapse }\end{array}$ & $\begin{array}{l}\text { Relapsed } \\
(n=63)\end{array}$ & $\begin{array}{l}\text { Drug free } \\
(n=25)\end{array}$ & $P$ \\
\hline $\begin{array}{l}\text { Sessions of educational } \\
\text { programme attended } \\
\quad \geq 9 \\
\quad<9\end{array}$ & $\begin{array}{l}14(22 \%) \\
49(78 \%)\end{array}$ & $\begin{array}{r}18(72 \%) \\
7(28 \%)\end{array}$ & $<0.05$ \\
\hline $\begin{array}{l}\text { Age at onset, years } \\
\quad \leq 25 \\
>25\end{array}$ & $\begin{array}{l}38(60 \%) \\
25(40 \%)\end{array}$ & $\begin{array}{l}10(40 \%) \\
15(60 \%)\end{array}$ & NS \\
\hline $\begin{array}{l}\text { Marital status } \\
\text { Married } \\
\text { Unmarried }\end{array}$ & $\begin{array}{l}22(35 \%) \\
41(65 \%)\end{array}$ & $\begin{array}{r}16(64 \%) \\
9(36 \%)\end{array}$ & $<0.05$ \\
\hline $\begin{array}{l}\text { Family history of addicti } \\
\text { Positive } \\
\text { Negative }\end{array}$ & $\begin{array}{l}44(70 \%) \\
19(30 \%)\end{array}$ & $\begin{array}{r}5(20 \%) \\
20(80 \%)\end{array}$ & $<0.05$ \\
\hline $\begin{array}{l}\text { Employment status } \\
\text { Employed } \\
\text { Unemployed }\end{array}$ & $\begin{array}{l}21(33 \%) \\
42(67 \%)\end{array}$ & $\begin{array}{r}22(88 \%) \\
3(12 \%)\end{array}$ & $<0.05$ \\
\hline
\end{tabular}

NS, not significant.

After 12 years, in 2002, an attempt was made to trace the sample with the help of local social workers.

\section{Results}

Of the 137 patients, 49 (36\%) had dropped out and 88 (64\%) were followed up. Among the 88 followed up, 63 (72\%) had relapsed and $25(28 \%)$ had maintained their drug-free status. Among those who had relapsed, 42 (67\%) were using heroine, while 21 (33\%) had started using other drugs, such as benzodiazepines, alcohol and cannabis, in addition to heroin.

Of the 25 who had maintained their drug-free status, $18(72 \%)$ had attended 9 or more of the 15 sessions of the educational programme, whereas among the 63 who had relapsed, only 14 (22\%) had attended 9 or more sessions.

Of the 63 patients who had relapsed, 38 (60\%) had been aged 25 years or below at the onset of addiction, 22 (35\%) were married, 44 (70\%) had a family history of addiction and $21(33 \%)$ were employed.

Of the 25 patients who had maintained their drug-free status, $10(40 \%)$ had been aged 25 years or below at the onset of addiction, 16 (64\%) were married, 5 (20\%) had a family history of addiction and 22 (88\%) were employed.

Results indicated that factors preventing relapse included regular attendance at follow-up educational visits $\left(\chi^{2}=19.1\right.$, d.f. $=1, \quad P<0.05)$, being married $\left(\chi^{2}=6.16\right.$, d.f. $=1$, $P<0.05)$, absence of family history of drug addiction $\left(\chi^{2}=18.0\right.$, d.f. $\left.=1, P<0.05\right)$, and employment $\left(\chi^{2}=21.4\right.$, d.f. $=1, P<0.05)($ Table 1$)$.

\section{Discussion}

In the present study, out of 137 patients, 88 (64\%) could be traced and 49 (36\%) could not (some had changed their residences or gave the wrong address, and some had died). The relapse rate was high, at $72 \%$. Drug-free status was associated with employment, being married and no family history of addiction, similar to the findings of Bacchus et al (2000).

In this study, the majority of the participants who maintained their drug-free status attended 9 or more of the 15 sessions of the educational programme, whereas those who relapsed attended fewer. A similar result was reported by Perneger et al (1998) in Geneva. They found that a heroin maintenance programme is a feasible and clinically effective treatment for heroin users who fail in conventional drug treatment programmes.

In the present study, a majority of those who were drug free were married. Being married protects against relapse. It provides a confiding relationship, support and a sharing of responsibilities. The lower relapse rate among those who had no family history of addiction may be due to stable living conditions, adequate social (family) support and a healthy home atmosphere (Loimer et al, 1992).

This study found that the majority of patients who relapsed $(38,60 \%)$ had an age at onset of addiction of 25 years or less, although age difference at onset had no statistically significant effect on drug status in this sample. Chaudhry et al (1991) suggested that there is an increased prevalence of opium use in the younger age-group and mentioned the relationship between family history of addiction and age at onset. In spite of using different research designs, the results of both studies were in a similar direction.

In the present study, a strong association was seen between employment status and relapse rate. Employment may be protective against relapse because it enhances social stability and mental health. This finding is similar to that reported by Hser et al (2001).

\section{References}

Bacchus, L., Strang, J. \& Watson, P. (2000) Pathways to abstinence: two year follow up data on 60 abstinent men opiate addicts who had been turned away from treatment. European Journal of Addiction, 11, 141-147.

Chaudhry, H. R., Arria, A. \& Tarter, R. (1991) Familial history of opium use and reported problems among opium addicts in Pakistan. British Journal of Addiction, 86, 785-788.

Hser, Y. I., Hoffman, V. \& Grella, C. E. (2001) A 33 year follow up of narcotic addict. Archives of General Psychiatry, 58, 503-508.

Loimer, N., Hofmann, P. \& Chaudhry, H. R. (1992) Nasal administration of naloxone for detection of opiate dependence. Journal of Psychiatric Research, 26, 39-43.

Metrebian, N., Shanahan, W. \& Wells, B. (1998) Feasibility of prescribing injectable heroin and methadone to opiate-dependent drug users: associated health gains and harm reductions. Medical Journal of Australia, 168, 596-600.

Perneger, T. V., Giner, F. \& Del Rio, M. (1998) Randomized trial of heroin maintenance programme for addicts who fail in conventional drug treatments. BMJ, 317, 13-18

Robins, L. N. (1993) Vietnam veterans' rapid recovery from heroin addiction: a fluke or normal expectation? Addiction, 88, 1041-1054.

Robson, P. (1992) Opiate misusers: are treatments effective? In Practical Problems in Clinical Psychiatry (eds K. Hawton \& P. Cowen), pp. 141-158. Oxford University Press.

Rasheed, A., Chaudhry, H. R., Lali, M. S., et al (1992) Identification and quantitative determination of morphine in urine of heroin dependents. Pakistan Journal of Pharmacy, 5, 101-109.

Zhang, Z., Friedmann, P. D. \& Grestein, D. R. (2003) Does retention matter? Treatment duration and improvement in drug use. Addiction, 98, 673-684. 